1. Assistant Professor \& Head Department of Prosthodontics, Hamdard College of Medicine \& Dentistry, Karachi

2. Assistant Professor \& Head Department of Periodontology, Hamdard College of Medicine \& Dentistry, Karachi

3. Associate Professor, Department of Oral Surgery, Hamdard College of Medicine \& Dentistry, Karachi

4. Lecturer

Department of Prosthodontics, Hamdard College of Medicine \& Dentistry, Karachi

5. Lecturer

Department of Prosthodontics, Hamdard College of Medicine \& Dentistry, Karachi

6. Lecturer

Department of Prosthodontics, Hamdard College of Medicine \& Dentistry, Karachi

Correspondence Address: Dr. Mehmood Hussain House No. A-695, Block H,

Northnazimabad, Karachi

mhussain26@hotmail.com

Article received on:

18/11/2013

Accepted for Publication

06/04/2014

Received after proof reading:

$16 / 08 / 2014$

\section{RETENTION IN MANDIBULAR OBTURATORS}

\author{
Dr. Mehmood Hussain 1 , Dr. Syed Imran Hassan², Dr. Syed Kashif Naqvi ${ }^{3}$, \\ Mohammad Yawar Khan ${ }^{4}$, Moin Khan ${ }^{5}$, Waqas Tanveer ${ }^{6}$
}

ABSTRACT... Objective: To provide various means of retention in fabrication of mandibular obturators for patients visited Hamdard University Dental Hospital, Karachi. Study Design: It was a descriptive type of study. Place and Duration of study: The study was carried out at Hamdard University Dental Hospital, Karachi. Total duration of this study was two years. Materials and Methods: Nine patients were selected by purposive non-probability sampling technique. After taking consent, self designed Proforma was filled. Age ranged from 13-72 years. Six of them were males and three females. One of them was already using obturator. With the help of obtained information, various means of retention in maxillary obturator were provided. Results: Interim Obturators were fabricated for six patients while definitive obturators were fabricated for three patients. In eight patients conventional means of retention were employed while implant supported obturator was provided for one patient. Seven patients were satisfied with the performance of obturator. In one patient sectional tray was used for impression while in one patient artificial teeth were arranged by neutral zone technique. Regular follow up was carried out till one year. Conclusions: Utilization of various means of retention brings better compliance in mandibular defect patients provided with obturators.

Key words: $\quad$ Obturators, mandibular defect, retention, clasp, implant

Article Citation: Hussain M, Hassan SI, Naqvi SK, Khan MY, Khan M, Tanveer W. Retention in mandibular obturators. Professional Med J 2014;21 (4): 755-759.

\section{INTRODUCTION}

Obturator is derived from Latin word "Obturare" which means to stop up. It is a maxillofacial prosthesis used to close a congenital or acquired tissue opening, primarily of the hard palate or contiguous alveolar/ soft tissue structures'.

Obturator can be made up of acrylic resins or silicone and can incorporate dental, palatal, nasal or speech bulb components to fill the defect which can be due to surgical, congenital or as a result of surgical resection ${ }^{2}$.

Mandibular defects are less common than maxillary defects but pose more problems during fabrication of mandibular obturators. It is due to the presence of highly mobile tongue along with less surface area available for support ${ }^{3}$.

Due to the presence of mandibular defects patients can have inadequate lip support, improper speech, drooling of saliva, decrease masticatory efficiency and compromise esthetics ${ }^{4}$.

Multidisciplinary approach is required for oral rehabilitation of patients with mandibular defect, in which role of Prosthodontist is very important. Before provision of prosthesis certain factors like volume of the defect, positioning of remaining hard and soft tissues to be used for retention, stabilization, and support of the prosthesis, presence of teeth, selection of abutment, type of clasps should be considered during fabrication of obturator $^{5}$.

Before fabrication of obturator it is better to classify the mandibular defect. After classification it is easy to make an obturator of appropriate design considering all the fundamental principles of obturator designing. Cantor \& Curtis classification 
for partial mandibulectomy can be used in this regard $^{6}$.

For better compliance of patients wearing mandibular obturators like other dental prosthesis adequate mechanical qualities in obturators are required. Achievement of adequate retention is one of the primary requirements for better performance of obturator. Retention is defined as "quality inherent in the dental prosthesis acting to resist the forces of dislodgement along the path of placement"'.

Retention can be obtained mostly by means of conventional clasps. Following basic principles of clasp designing, tooth which is adjacent and farthest from the defect should be selected as abutment tooth. When situation favors then incorporation of indirect retainer can also improve retention effectively ${ }^{8}$.

After surveying, identification and utilization of favorable undercut on dentate side can also help to achieve retention as well. The use of alternate buccal and lingual undercut will further enhance the retention'. The concept of neutral zone can also be employed during impression for better mechanical qualities in mandibular obturator ${ }^{10}$.

The use of other means like precision attachment, magnets, springs, two parts obturator can be very useful in achieving retention. Utilization of these gadgets is very beneficial in situations where placement of conventional clasps is difficult due to limited mouth opening ${ }^{11}$.

Where situation favors use of telescopic crowns/ coping for mandibular obturator can be employed to achieve better retention. Before provision of telescopic crowns/ coping certain factors like lower facial height, status of abutment teeth, time and cost should be considered ${ }^{12}$.

Provision of implant supported obturator brings wonderful improvement in performance of obturator by exhibiting better mechanical qualities. Incorporation of dental implants in obturators not only serves as a primary source or retention for prosthesis but can also be used successfully in conditions where bone augmentation or bone graft is used to cover the defect $^{13}$.

\section{MATERIAL \& METHODS}

It was a descriptive type of study and was carried out at the Department of Prosthodontics, Hamdard University Dental Hospital, Karachi. The duration of study was two years. Nine patients were selected by purposive non-probability sampling technique. After taking consent, self designed Proforma was filled. Age ranged from 13-72 years. Six of them were males and three females. One of them was already using obturator. With the help of obtained information, various means of retention in maxillary obturator were considered.

\section{RESULTS}

Interim Obturators were fabricated for six patients while definitive obturators were fabricated for three patients. In eight patients conventional means of retention were employed while implant supported obturator was provided for one patient. The concept of neutral zone for teeth setup was used in one patient. Seven patients were satisfied with the performance of obturator. Regular follow up was carried out till one year.

Five patients need adjustments in their obturator, three of them were those in which marsupialization procedure was done and due to changes in the surrounding tissues adjustments are inevitable. Two patients reported with problem in mastication due to cramping of tongue which was due to lingual placement of artificial teeth. The problem was resolved on follow up visits by grinding of lingual cusps of artificial teeth. One patient did not satisfy with the performance of obturator and refused to wear it further.

\section{DISCUSSION}

Maxillofacial defects can be due to surgical resection, infections, trauma or congenital reasons. As a result such patients have compromised esthetics with decrease functional efficiency along with psychological disturbances 
as well. Multidisciplinary approach is required for rehabilitation of such patients in which Prosthodontist can play a major role ${ }^{14}$.

To achieve better performance of obturators, it is necessary to utilize various means to have adequate retention in obturator for better functions and improve esthetics which in turn affects the psychology of such patients ${ }^{15}$.

Traditional ways to achieve retention in partial dentures are equally effective in mandibular obturators. King et $\mathrm{al}^{16}$ discussed the role of conventional clasps in achievement of retention in obturator. In this study conventional clasps were provided to all patients.

Some times modification in obturator design may be required, Nakamura et $\mathrm{al}^{17}$ discussed a case report in which labial bar was used to achieve better mechanical qualities. In this study, labial bar was fabricated for one patient where it was difficult to achieve retention from lingual side.

Proper impression is an important prerequisite for achievement of retention, which in certain conditions due to limited mouth opening is very difficult. In these patients sectional impression trays can be used to make impression. Samet et $\mathrm{al}^{18}$ discussed a clinical report where sectional tray was used to make mandibular removable partial denture in patient presented with limited mouth opening. In this study sectional tray was used in one who patient who also presented with limited mouth opening which was due to radiation therapy after partial mandibulectomy.

Kokubo et $\mathrm{al}^{19}$ cussed a case report in which artificial teeth was arranged by utilizing the concept of neutral zone. In this in one case teeth were also arranged by neutral zone technique.

Hotta et $\mathrm{al}^{20}$ notified the importance of adjustments in obturator on follow up visits, they discussed a case report in which a patient had problem during mastication due to slight lingual arrangement of artificial teeth, which was corrected by reduced vertical dimension on follow up visits. In this study two patients had similar complain which was corrected on follow up visits by slight grinding of lingual cusps of artificial teeth along with slight reduction in occlusal vertical dimension.

Those patients who reported for provision of mandibular obturator after marsupialization/ enucleation of cysts may also require regular adjustments on follow up visits due to changes in the surrounding oral tissues. Sakkas et al discussed a case where adjustments were made in mandibular obturator after marsupialization of radicular cyst.

These adjustments some times may compromise retention and stability which can be improved by relining procedure ${ }^{21}$.

In this study three patients were reported after marsupialization procedure for mandibular obturator and after fabrication of obturators adjustments were made on subsequent follow up visits.

Varjao et $\mathrm{al}^{22}$ discussed the importance of myofuntional therapy as an aid to prosthodontic treatment for better mechanical qualities in those patients who had undergone golssectomy as well. In this study myofunctional therapy was utilized for one patient who had partial glossectomy and Fig2. Intra oral view showing mandibular over denture significant result was obtained.

The concept of telescopic crown or metal coping on suitable tooth/ teeth of resection side can be used effectively as an abutment for mandibular obturator cum over denture, space must be created in obturator to accommodate the telescopic crown/ coping. This will not only improve the abutment tooth/ teeth health but also aid in achievement of adequate mechanical qualities. Shukla et $\mathrm{al}^{23}$ elaborated that for successful outcomes in patients of mandibular obturator innovations and modifications are needed. In this study in one patient metal coping (Fig 1 \& 2) was used on two teeth on in order to achieve better retention and patient was satisfied with the performance of mandibular obturator. Gollner et al also discussed a case report in which 
telescopic over dentures were provided for patient suffered from osteoradionecrosis in lower jaw ${ }^{24}$.

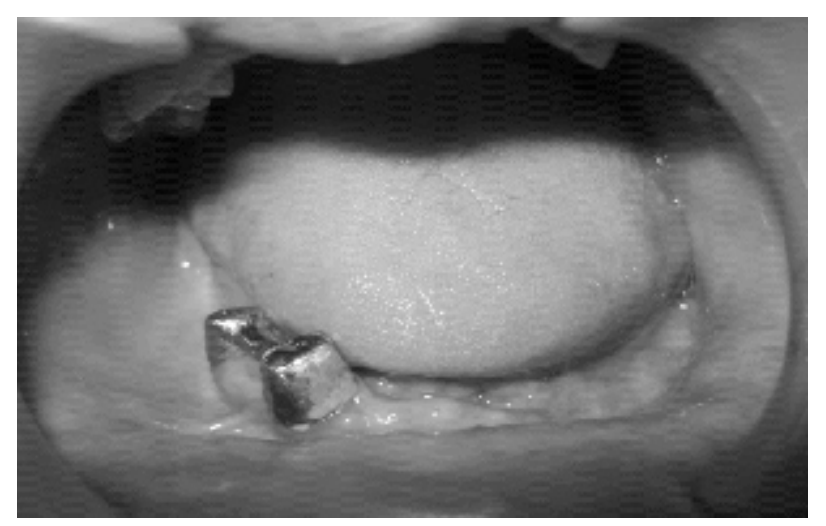

Fig-1. Intra oral view showing mental coping

With introduction of dental implants in Maxillofacial Prosthodontics, there is marked improvement in achieving retention in mandibular obturators. Christian et $\mathrm{al}^{25}$ reported a case in which implant supported prosthesis was provided for patient with posterior mandibular resection and good results were achieved. In this study one patient was provided with implant supported obturator and retention was far better than his interim conventional mandibular obturators.

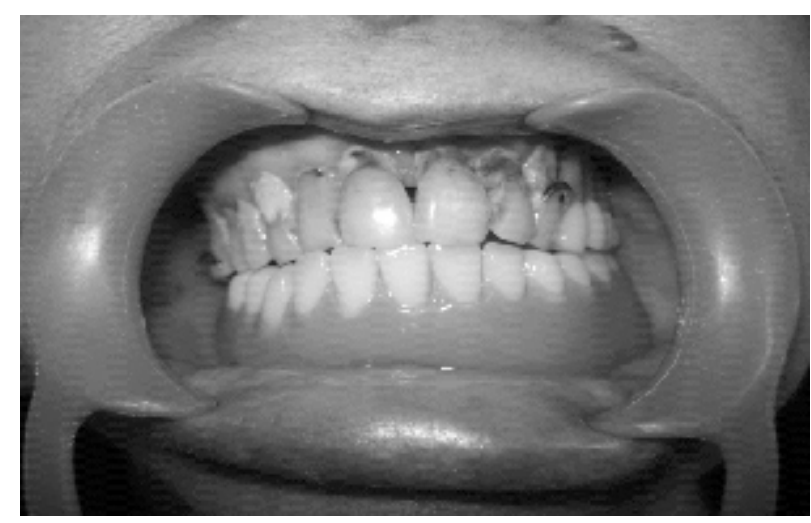

Fig-2. Intra oral view showing mandibular over denture

In this study no surgical obturator was fabricated which may due to lack of awareness about significance of surgical obturator in patient or oral surgeon. This can also be due to poor coordination between oral surgeon and Prosthodontist.

Schneider et $\mathrm{al}^{26}$ elaborated the significance of team work for rehabilitation of oral cancer patients. He discussed a clinical report in which oral surgeon and prosthodontist worked in a group for rehabilitation of patient operated for partial mandibulectomy followed by fabrication of obturator.

\section{CONCLUSIONS}

Multidisciplinary approach is required for oral rehabilitation of patients with mandibular defect. By provision of obturator with adequate mechanical qualities can be of great help for these patients to improve their mastication, speech and esthetics. With improvement in these domains will result in better self esteem for these patients to become an active member of the society.

Copyright $@ 06$ Apr, 2015.

\section{REFERENCES}

1. Ahmed B, Hussain M, Yazdanie N. Hollow bulb obturator: A blessing for maxillextomy patient. A case report. Pak Oral dent J 2007; 27: 127-28.

2. Ahmed B, Hussain M, Butt AM, Yazdanie $N$. Maxillofacial rehabilitation of a large cleft palate using fixed- removable prosthesis. J Coll Physicians Surg Pak 2011; 21: 52-54.

3. Burnett CA, Clifford TJ. Prosthodontic rehabilitation of patients with orofacial defects. Dent Update 2012; 39: 291-96. Shifman A, Lepley JB. Prosthodontic management of post surgical soft tissue deformities associated with marginal mandibulectomy. Part I: Loss of the vestibule. J Prosthet Dent 1982; 48: 178-83.

4. Cheng AC, Wee AG, Morrison D, Maximiw WG. Hinged mandibular complete denture for post mandibulectomy patients. J Prosthet Dent 1999; 82: 103-6.

5. Siddal KZ, Rogers SN, Butterworth CJ. The Prosthodontic pathway of the oral cancer patient. Dent Update 2012; 39: 98-100.

6. Carr AB, McGiveney GP, Brown DT. Removable partial denture considerations in maxillofacial prosthetics. McCraken's removable partial Prosthodontics. 11th ed. India: Elsvier 2005; 397420. 
7. Stewart KL, Rudd KD, Kuebker WA. Principles of removable partial denture. Clinical Removable Partial Prosthodontics. $2^{\text {nd }}$ ed. India: AIPD 2005; 97116.

8. Parr GR, Gardner LK. The evolution of the obturator framework design. J Prosthet Dent 2003; 89: 608-09.

9. Jacob RF, King GE. Partial denture framework design for bone-grafted mandibles restored with osseointegrated implants. J Prosthodont 1995; 4: 06-10.

10. Wee AG, Cwynar RB, Cheng AC. Utilization of the neutral zone technique for a maxillofacial patient. J Prosthet Dent 2000; 9: 02-07.

11. Murat S, Gurbuz A, Isayev A, Dokmez B, Cetin U. Enhanced retention of a maxillofacial prosthetic obturator using precision attachments: Two case reports. Eur J Dent 2012; 6: 212-17.

12. Burnett CA, Clifford TJ. Prosthodontic rehabilitation of patients with orofacial defects. Dent Update 2012; 39: 291-96.

13. Kim DD. Ghali GE. Dental implants in oral cancer reconstruction. Dent Clin North Am 2011; 55: 87182.

14. Deng H, Sambrook PJ, Logan RM. The treatment of oral cancer: an overview for dental professionals. Aust Dent J 2011; 56: 244-52.

15. Patton DW, Davies R, Fardy MJ. Oral rehabilitation and quality of life following the treatment of oral cancer. Dent Update 1994; 21:231-4.

16. King GE, Martin JW. Cast circumferential and wire clasps for obturator retention. J Prosthet Dent 1983; 49: 799-802.

17. Nakamura SH, Martin JW, King GE, Kramer DC. The labial plate major connector in the partial mandibulectomy patient. J Prosthet Dent 1989; 62: 673-5.
18. Samet N, Tau S, Findler M, Susrala SM, Findler M. Flexible removable partial denture for a patient with systemic sclerosis (scleroderma) and microstomia: a clinical report and a three year follow up. Gen Dent 2007; 55: 548-51.

19. Kokubo Y, Fukushima S, Seto K. Arrangement of artificial teeth in the neutral zone after surgical reconstruction of the mandible: A clinical report. J Prosthet Dent 2002; 88: 125-7.

20. Hotta H, Kanai Y, Yashmila S. Repeated adjustment of new dentures for dysphagia. Bull Tokyo Dent Coll 2012; 53: 173-80.

21. Sakkas N, Schoen R, Schulze D, Otten JE, Schmelzeisen R. Obturator after marsupialization of a recurrence of a radicular cyst of the mandible. Oral Surg Oral Med Oral Pathol Oral Radiol Endodod 2007; 103: 16-8.

22. Varjao FM. Myofunctional therapy as an aid to prosthodontic treatment after hemiglossectomy: a clinical report. J Prosthet Dent 2012; 107: 284-7.

23. Shukla P, Hegde C, Rampal N, Pawah S, Gupta A, Shukla M. Modified technique for a patient with segmental mandibulectomy. A case report. Eur $\mathrm{J}$ Prosthodont Restor Dent 2011; 19: 175-8.

24. Gollner M. Holst S, Fenner M, Schmitt J. Prosthodontic treatment of a patient with biphosphonate induced osteoradionecrosis of the jaw using a removable dental prosthesis with a heat- polymerized resilient liner. J Prosthet Dent 2010; 103: 196-201.

25. Christian J, Grover M, Veeravalli PT. Replacement of mandibular posterior teeth with implants in a postmandibular resection case: a case report. $J$ Oral Implantol 2013; 39: 210-3.

26. Schneider R, Fridrich K, Funk G. Complex mandibular reconstruction after a partial mandibulectomy with a fibula free graft: a clinical report. J Prosthet Dent 2013; 110: 223-7. 